\title{
Turismo, urbanismo y colonialismo en Tánger, 1880-1939*
}

\author{
Sasha D. PACK \\ Universidad de Buffalo, State University of New York \\ sdpack@buffalo.edu
}

Recibido: $22 / 04 / 2015$

Aceptado: 02/07/2015

\section{RESUMEN}

Este artículo examina el ocio, los viajes y el turismo durante el período de mayor expansión urbana de Tánger. Varios factores favorecieron las posibilidades de Tánger para desarrollar una economía basada en los viajes y el ocio, entre ellas, el clima, su localización geográfica, la disponibilidad de una masa laboral procedente de Marruecos y el sur de Andalucía y el papel de la ciudad como sede euro-marroquí para la inversión, el comercio y la diplomacia.

La ciudad era conocida por miles de viajeros y turistas residenciales desde finales del siglo XIX, lo que fomentó un optimismo considerable por lograr un mayor crecimiento de esta zona. Sin embargo, durante los años treinta una sucesión de problemas políticos locales e internacionales impidieron la consolidación de la ciudad como un gran destino turístico.

Palabras clave: Tanger, Turismo, Urbanismo, Colonialismo.

\section{Tourism, Urbanism and Colonialism in Tangier, 1880-1939}

\begin{abstract}
This article examines leisure, travel, and tourism during the period of rapid urban expansion of Tangier. Several factors favored Tangier's prospects to develop an urban economy based on travel and leisure, including climate, location, the availability of a labor force from Morocco and southern Andalucía, and the city's role as the seat of Euro-Moroccan investment, commerce, and diplomacy. It was known to thousands of travelers and residential tourists by the late nineteenth century, fuelling considerable optimism for further growth in this area. By the 1930s, however, a range of municipal and inter-imperial political problems impeded the city's consolidation as a major resort destination.
\end{abstract}

Key words: Tangier, Tourism, Urbanism, Colonialism.

\footnotetext{
${ }^{*}$ Este trabajo forma parte del proyecto de investigación HAR2011-23214, financiado por el Ministerio de Economía y Competitividad.
} 


\section{Introducción}

Tánger es un antiguo asentamiento de origen cartaginés pero su crecimiento como ciudad está ligado a conceptos tan modernos como la movilidad, la salubridad y el exotismo. De ser una pequeña ciudad de nueve mil habitantes a finales de la década de 1860, Tánger creció precipitadamente, desde finales del siglo XIX y los primeros años del siglo XX, hasta alcanzar en 1925 los 50.000 habitantes, de los que un tercio eran de origen europeo. ${ }^{1}$ Este crecimiento se basa en varios factores relacionados con su específica coyuntura geográfico-histórica. La rivalidad de los imperios europeos en el Mediterráneo occidental evitó que un único poder conquistara la hegemonía en Tánger, dando como resultado una colonización plural bajo el gobierno, meramente nominal, del Sultán. Tánger estaba especialmente bien situada para gestionar un aumento de la circulación marítima ya que su puerto, mejor situado que el de Tetuán, podía alojar a los grandes vapores de la época y, gracias a su Consejo Sanitario compuesto por médicos consultores europeos, estaba mejor equipado para controlar epidemias como el cólera. ${ }^{2}$ De esta manera, Tánger adquirió fama como la ciudad marroquí más saludable, más accesible y más cosmopolita, un estatus que condicionó su espectacular desarrollo urbano entre 1880 y 1939.

Los viajes y el turismo conforman el principal componente de ese amplio desarrollo urbanístico. Durante la última parte del siglo XIX, Tánger y Gibraltar se convirtieron en los puntos de entrada y salida de un número creciente de pasajeros. Además del frecuente ir y venir del personal diplomático y militar, los dos puertos atrajeron una corriente permanente de comerciantes, marineros y un no menor número de viajeros alentados por las guías Baedeker, los relatos de Richard Ford y otras guías que recomendaban empezar los viajes por España desde el Estrecho. ${ }^{3}$ Aunque el clásico tour turístico por España no desapareció, un nuevo género de guías y diarios de viaje combinaban el Sur de España y el Norte de Marruecos. ${ }^{4}$ En las últimas ediciones de su icónica guía de España, el hispanófilo británico Richard Ford recomendaba a los viajeros que recorrían Andalucía que visitaran Tánger y sus alrededores (mientras que las posesiones africanas de Ceuta y Melilla ni se mencionan). ${ }^{5}$ Baedeker también incluyó información para realizar una excursión a Tánger. Unos cuantos escritores de viajes de finales del siglo XIX, incluyendo al menos un andaluz, narraron sus viajes a través del Sur de España y el Norte de Marruecos. ${ }^{6}$

1 PARSONS, Frederick V.: The Origins of the Morocco Question, 1880-1900, Londres, Duckworth, 1976, pp. 539-540; MIÈGE, Jean-Louis: Le Maroc et l'Europe, t. IV, París, Presses Universitaires de France, 1961, p. 294.

2 MIÈGE, Jean-Louis, BENABOUD, Mohammed, y ERZINI, Nadia: Tétouan: ville andalouse marocaine, París, CNRS, 1996, p. 74.

3 FORD, Richard: A Handbook for Travellers in Spain, Londres, John Murray, 1889; BAEDEKER, Karl, Baedeker's Spain and Portugal, 3ª ed., Leipzig, Karl Baedeker, 1908, p. xiii.

4 REYNOLDS-BALL, Eustace: Mediterranean Winter Resorts, 3a ed., Londres, Paul Kegan, 1896; PLAYFAIR, Robert: Handbook to the Mediterranean, Londres, John Murray, 1882.

5 FORD, Richard: Handbook ...

6 JEREZ PERCHET, Augusto: Impresiones de viaje. Andalucía-El Riff-Valencia-Mallorca, Málaga, Correo de Málaga, 1870; MARTÍNEZ GARCÍA, Ramón: Una excursión en diez y seis jornadas por Córdoba, Sevilla, Cádiz, Tánger, Cabo Espartel, Gibraltar, Algeciras, Ronda, Bobadilla, Málaga, Granada y casa, Madrid: Est. Tip. de la Viuda e Hijos de Tello, 1897; HESSE-WARTEGG, Ernst von: Eine Winterreise durch 
Muchos historiadores del turismo han identificado ampliamente el nexo entre Turismo y Colonización, sobre todo en el Mediterráneo de estos años. Mientras escribía en el volumen de 1930 del Journal of Modern History, el historiador estadounidense Hugo C. M. Wendel identificó el libre movimiento de turistas por Marruecos como un claro indicador de colonización: "Potentes autobuses de lujo recorren el país de una punta a otra con itinerarios programados", observó Wendel. "El brazo protector de Francia ha creado seguridad para que los extranjeros puedan viajar donde quieran tanto en zonas civiles como militares sin necesidad de armas". 7 A estas alturas del imperialismo europeo, la perspicacia de Wendel anticipó el trabajo de las siguientes generaciones de historiadores sobre la conexión entre turismo y colonización. La habilidad de los europeos, muchas veces simples turistas, para dejar atrás los enclaves costeros sin protección armada forma parte importante del proceso de asentamiento. Empresas de transporte invirtieron en los asentamientos y cultivos europeos de Marruecos, sobre todo, la francesa Compagnie Générale Transatlantique y la Gibraltar's Bland Line. Hacia 1920, estas firmas también tenían participación en la mayor parte de hoteles y empresas de viaje, organizando viajes escolares y otras formas de turismo con la esperanza de motivar a futuros colonos. Las apreciadas Guías Azules de Michelin imprimían una nueva edición de Marruecos "con cada nueva ampliación de las zonas de seguridad." ${ }^{8}$ Como Alet Valéro ha demostrado, iniciativas similares llegaron al Marruecos español después de 1928, pero la brecha que separa lo potencial de lo real seguía siendo muy amplia. ${ }^{9}$

La experiencia de Tánger revela un aspecto diferente de la relación entre viajes y colonización. Más que contribuir a las demandas colonialistas, el turismo y otras formas de viaje se apuntalaron por la posición estratégica de la ciudad como punto de conexión entre los imperios británico, francés, español y marroquí. Encaramado en la frontera entre dos mundos, en un enclave de clima suave bañado por el sol donde el Mediterráneo se une al Atlántico, el rápido crecimiento de Tánger se configuró gracias a la convergencia de varios factores como la apertura del canal de Suez en 1869, la moda creciente del hivernant y el "Reparto de África". En cierto sentido, ésta es la historia de la colonización europea de Marruecos, que atrajo a un grupo cosmopolita de empresarios y funcionarios con sus familias junto con una numerosa clase trabajadora compuesta fundamentalmente por marroquíes y españoles de las zonas cercanas a ambos lados del Estrecho. El contingente español era el más numeroso de las comunidades europeas de Tánger, pasando de unos 5.000 en 1892 a 10.000 hacia 1925,

Südspanien und ein Ausflug nach Tanger, Leipzig, Verlag von Karl Reisner, 1894; ZAMACOIS, Eduardo: De Córdoba a Alcazarquivir: tipos y paisajes de Andalucía y Marruecos, 1915-1921, Barcelona, Maucci, 1921.

7 WENDEL, Hugo C. M.: "The Protégé System in Morocco," The Journal of Modern History, Chicago, $\mathrm{n}^{\circ}$ 1, vol. 2 (1930), p. 48.

8 BOUTBOUQALT, Tayeb: "Mobilités coloniales et propagande touristique au Maroc. Fondements et processus d'évolution", en Colette ZYTNICKI y Habib KAZDAGHLI (eds.), Le tourisme dans l'empire français: politique, pratiques, et imaginaires (XIXe-XXe siècles), París, Société Française d'Histoire d'Outre Mer, 2009, p. 106. De la misma edición, véase KAZDAGHLI, Habib: "L'Entrée du Maghreb dans les circuits du tourisme international: le rôle précurseur de la Compagnie Générale Transatlantique", pp. 205-215.

9 VALERO, Alet: "Le tourisme au Maroc espagnol. La période du Patronato Nacional del Turismo (19281936)”, en Colette ZYTNICKI y Habib KASDAGHLI (eds.), Le tourisme ..., pp. 235-254. 
eclipsando a la siguiente comunidad más numerosa, la de los británicos gibraltareños, en una proporción de 10 a $1 .{ }^{10}$

Pero la expansión de Tánger no se debe entender exclusivamente en términos NorteSur o Metrópolis-Colonia. También es la típica historia del litoral del Mediterráneo occidental. Para la élite acaudalada y cosmopolita, la Costa Azul se transformó, a lo largo del siglo XIX, en un modelo de estación de invierno, embellecida con flora tropical importada y grandes paseos. Unos cuantos enclaves costeros de Andalucía, de la costa adriática y del Magreb copiaron un modelo similar, incluso sabiendo que no podrían competir con el prestigio de la Riviera franco-italiana. Argel, una ciudad con modernas infraestructuras y entretenimientos, atraía a unos 1.500 hiverneurs cada año, incluyendo a un desafortunado Karl Marx durante un invierno especialmente lluvioso en 1882-83. ${ }^{11}$ En la primera década del siglo XX, una combinación de compañías navieras, cadenas hoteleras y asociaciones municipales se unieron para promocionar el turismo en varias ciudades del Mediterráneo occidental.

Una mala opinión sobre el Mediterráneo teñía la visión imperante de los colonos europeos acerca del futuro de Tánger, donde la suciedad, el contagio y los conflictos religiosos tenían que ser sustituidos por brisas suaves, la luz del sol y los intercambios culturales bajo la tutela de la beneficiosa civilización moderna europea. En la Conferencia de Madrid de 1880 sobre la cuestión marroquí, los poderes europeos presionaron al Sultán para que diera carta blanca a nuevas construcciones europeas en Tánger y otros puertos. El primer hotel de Tánger, el Continental, abrió ese mismo año; otros más le siguieron a lo largo de las siguientes décadas bajo titularidad francesa, británica y española. ${ }^{12}$ Este desarrollo dio pie a la observación que el escritor de viajes Pierre Loti hizo sobre el Sultán: "posee todo pero ha abandonado la ciudad a los visitantes extranjeros, mirándola con más desapego que si fuera una ciudad de infieles". ${ }^{13}$ En la edición de 1890 de la popular guía Murray se predijo una nueva oleada de construcciones "ya que Tánger está siendo cada vez más popular como destino de invierno". ${ }^{14}$ El inglés James Edward Budgett-Mealin en su revista Times of Morocco promocionó activamente el potencial de Tánger recordándoles a los lectores que la ciudad tenía 300 días de sol al año y citando la declaración del British Medical Journal de 1894 que reconocía a Tánger como el primer destino de salud del Norte de África. ${ }^{15}$ Eustace Reynolds-Ball, en su Mediterranean Winter Resorts, es menos

\footnotetext{
10 PARSONS, Frederick V.: Morocco Question ..., pp. 539-540.

11 JORDI, Jean-Jacques: “Le temps des hiverneurs: les 'anglais' en Algérie (1880-1914)", en Colette ZYTNICKI y Habib KASDAGHLI (eds.), Le tourisme ..., pp. 29-35; BOYER, Marc: L'Invention de la Côte d'Azur. L'hiver dans le midi, La Tour d'Aiguës: Éditions de l'Aube, 2002; PEMBLE, John: The Mediterranean Passion: Victorians and Edwardians in the South, Oxford, Clarendon, 1987.

12 CEBALlOS, Leopoldo: Historia de Tánger. Memoria de la ciudad internacional, Málaga, Almuzara, 2009, p. 177.

13 LOTI, Pierre: Au Maroc, París, Calman Lévy, 1890, p. 25.

14 Citado en MILLER, Susan Gilson: "Making Tangier Modern: Ethnicity and Urban Development, 18801930" en Emily BENICHOU y Daniel J. SCHROETER (eds.), Jewish Culture and Society in North Africa, Bloomington, Indiana University Press, 2011, p. 132.

15 VAIDON, Lawton: Tangier: A Different Way, Metuchen, Scarecrow Press, 1977, p. 134.
} 
optimista sobre el "horrible" y "caótico" potencial de Tánger como centro de salud; sin embargo, recomienda la visita a esta fascinante ciudad y sus alrededores. ${ }^{16}$

Para algunos europeos mal informados, Tánger era una sinécdoque de todo Marruecos. En su diario de viaje de 1883, el diplomático español Wenceslao VillaUrrutia se quejaba de la cantidad de forasteros que basaban sus impresiones sobre Marruecos en una sola visita a Tánger. ${ }^{17}$ Aunque la mayor parte de los turistas que cruzaban el Estrecho permanecían en Tánger, es difícil medir su impacto para esta primera etapa. El recuento oficial de turistas no excedía de unos pocos cientos por año pero esas cifras sólo comprendían a aquellos que llegaban en barcos privados de recreo - un criterio que excluía a la mayor parte de escritores de viajes, por no hablar de comerciantes y otros viajantes cuyos viajes de negocios a África todavía tenían un componente de aventura turística-. El Boletín de la Cámara de Comercio española en Tánger observó en 1897 que turistas, que a menudo permanecían sólo unas horas, "no alteran la realidad de la población". ${ }^{18}$ Debemos perdonar a la Cámara por no incluir el turismo en su misión de promover el desarrollo industrial y comercial, sin embargo, su afirmación sigue siendo bastante limitada y engañosa. La circulación desde el Estrecho de gentes de aquí y allá, buscando lugares dinámicos y saludables, se convirtió en una característica fundamental de la historia social de Tánger en este período, ya fuera para hacer negocios, para conseguir entrar en las estructuras de poder local a través de la cultura del ocio, para pasar un invierno suave en un lugar salubre, para visitarlo por un día o, como para la mayoría, para establecerse en un lugar lleno de oportunidades. El reto de explotar sistemáticamente esta floreciente "industria de forasteros" animó a crear grandes coaliciones de inversores, líderes locales y simples residentes, a pesar del gran número de dificultades. El fácil acceso, el clima agradable y otros muchos encantos quedaban totalmente neutralizados por la falta de higiene y las deficientes infraestructuras e, incluso, por la evidente peligrosidad. Sin embargo, la aspiración por convertirse en un próspero enclave turístico fue el principal componente de su desarrollo urbano, de un asentamiento casi colonial e, incluso, de intereses imperialistas.

El optimismo floreciente de la ciudad durante las dos últimas décadas del siglo XIX surgía de la creencia de que ésta era un imán para el ocio, la salud y el comercio - un lugar seguro y salubre equidistante de cuatro poderes imperialistas, con una capacidad inagotable para obtener concesiones de un Majzén ansioso por mantener a los infieles en igualdad de condiciones. Los europeos eran los propietarios de la parte más sustanciosa de la industria de Tánger y, casi toda ella, servía a las necesidades de la expansión urbana. La mayor compañía española en Tánger, la Hispano-marroquí, empleaba a 200 españoles entre la construcción, las fábricas de ladrillos y las inmobiliarias. ${ }^{19}$ Además de las empresas constructoras españolas, las fábricas francesas producían ladrillos, cemento, madera, agua con gas, harina y cerillas. Otra industria

16 REYNOLDS-BALL, Mediterranean ..., pp. 313-316; idem., 7 ${ }^{\mathrm{a}}$ ed., Londres, Paul Kegan, 1915, p. 399.

17 RAMIREZ DE VILLA-URRUTIA, Wenceslao: Una embajada á Marruecos en 1882. Apuntes de viaje, Madrid, Impresores de la Real Casa, 1883, p. 11.

18 CÁMARA DE COMERCIO ESPAÑOLA EN TÁNGER: Revista de la Cámara de Comercio Española en Tánger, $\mathrm{n}^{\circ}$ 92, vol. 11 (1897), p. 12.

19 CÁMARA DE COMERCIO ESPAÑOLA EN TÁNGER: Revista ..., nº 39, vol. 4 (1890), p. 4. 
importante eran las destilerías alemanas que suministraban bebidas alcohólicas de baja graduación a la nueva clase trabajadora de españoles y judíos inmigrantes (los hoteles importaban sus licores desde Europa). La Compañía Transatlántica española, a pesar de que estuvo prácticamente en bancarrota en 1892 debido a su deficitario servicio de carga, mantuvo dos agentes en Tánger y financió la planta eléctrica de la ciudad. ${ }^{20}$

\section{Turistas y colonos}

Los turistas formaban una categoría de extranjero que no se distinguía completamente de otro tipo de viajeros ni de los colonos permanentes. Por lo tanto, debemos evitar insistir en la distinción categórica entre turista, viajero y colono. Aunque individuos de cada grupo solían ser transeúntes y residentes temporales, en conjunto, formaban una comunidad de personas protegidas que proporcionaban un flujo constante de importantes ingresos a las compañías de transporte y de servicios urbanos, y que hacían crecer la importancia de los cónsules que velaban por ellos. Como un indicador de esta ambigüedad, los cónsules europeos registraban como "residentes" a todo aquel que permaneciera en la ciudad, al menos, dos meses; un grupo que incluía unos 2.000 turistas británicos que venían cada año a disfrutar del templado invierno. ${ }^{21} \mathrm{Un}$ capellán anglicano se unió a la colonia de invierno entre 1881-82 y la mayor iglesia anglicana, San Andrés, abrió en 1894, ayudando a forjar un sentimiento colectivo de permanencia entre este grupo de residentes temporales. ${ }^{22}$

La frecuente rotación de personal militar y diplomático con sus familias, junto a la continua circulación de viajeros de todas clases, hicieron crecer negocios enfocados a facilitarles el viaje, a acomodar a los recién llegados y proporcionarles ocio. Los oficiales, cónsules y sus allegados rotaban frecuentemente, siendo el diez por ciento de la población de la ciudad hacia $1900 .{ }^{23}$ La constante necesidad de cocineros y jardineros para sus residencias, así como de encargados de mantenimiento de las cuadras y los vigilantes montados, daba oportunidades laborales a marroquíes e inmigrantes españoles. Un intérprete "listo y limpio" con conocimientos de árabe, español y algo de francés recibía una paga más que respetable de 3 duros y medio por semana. ${ }^{24} \mathrm{El}$ negocio de proteger a numerosos grupos de turistas en sus excursiones al campo era un importante medio de subsistencia para 30-40 hombres jóvenes, un grupo hetero-

20 CÁMARA DE COMERCIO ESPAÑOLA EN TÁNGER: Revista ..., no 100, vol. 13 (1899), p. 2; COUSIN, Albert, y SAURIN, Daniel, Le Maroc, París, Libairie du Figaro, 1905, pp. 241-242, 409; MARTíN CORRALES, Eloy, "El nacionalismo catalán y la expulsión colonial española en Marruecos: de la guerra de África a la entrada en vigor del Protectorado (1860-1912), en idem. (ed.), Marruecos y el colonialismo español (1859-1912): De la Guerra de África a la "penetración pacífica", Barcelona, Edicions Bellaterra, 2002, p. 200.

21 MIÈGE, Jean-Louis, L'Europe au Maroc, t. III, p. 474, and IV, pp. 294-295.

22 HOWARD-VYSE, Lady (Elizabeth Culme-Seymour): A Winter in Tangier and Home Through Spain, Londres, Hatchards, Picadilly, 1882, pp. 208-209.

23 CEBALLOS, Leopoldo: Historia de Tánger ..., p. 130.

24 HOWARD-VYSE, Lady: Winter in Tangier ..., p. 5. 
géneo de musulmanes, españoles y judíos residentes en Tánger. ${ }^{25}$ Además de las habilidades lingüísticas, eran necesarias habilidades cinegéticas porque había que asumir que no se conseguiría fácilmente comida en los pueblos. En las comarcas alrededor de Tánger, la presencia de cuidadas caravanas de turistas era tan habitual hacia 1880 que un oficial de la colonia británica confundió un campamento de oficiales de la Armada Majzén con un grupo de turistas gibraltareños bajo la escolta de "uno de los numerosos servicios de catering para los incansables viajeros británicos". ${ }^{26}$

Los turistas de todo tipo se mezclaban con otro tipo de viajeros. En el vapor procedente de Gibraltar, se confundían con comerciantes y trabajadores inmigrantes -cristianos judíos y musulmanes- que circulaban a través de la región en busca de clientes, financiación, trabajo, ocio o visitas a familiares. Aunque la mayor parte de los pasajeros venían de zonas cercanas como el Campo de Gibraltar o el Fahs, comarca cercana a Tánger, había otros muchos, desde los industriales alemanes que buscaban dónde establecer nuevas factorías hasta los soldados británicos con base en Gibraltar que aprovechaban unos días libres para disfrutar de los famosos cotos de caza de Tánger. En 1897, el Boletín Comercial de Puerto Rico publicó una serie de escritos de un "viajero", "turista" y "narrador de los interesantísimos relatos y las amenas y palpitantes descripciones" de Andalucía y Marruecos, una información que debió ser útil a los empresarios lectores que pronto se verían expulsados del Caribe. ${ }^{27}$ Miles de europeos se pusieron en marcha para conocer y establecer contactos locales en Tánger, quienes, a su vez, les ofrecían una fascinante mezcla de accesibilidad, exotismo y posibilidades ilimitadas. En 1890, el escritor de viajes francés Pierre Loti observó que "los altos parapetos de su fortaleza y sus minaretes cubiertos de azulejos antiguos" conservaban las reminiscencias del encanto oriental mucho mejor que Argel. ${ }^{28}$ Tánger era, además, un puerto obligatorio en la ruta de vuelta de La Meca para los peregrinos hajj, que pasaban la noche al lado de la tumba de un santo guerrero del siglo XVII antes de despojarse de sus ropas de peregrinaje. ${ }^{29}$

Entre los turistas europeos, los viajeros emprendedores y los trabajadores inmigrantes que llegaban a Tánger, sólo los más intrépidos se aventuraban a ir más lejos. Viajar al interior conllevaba un gasto considerable e incomodidades; los exagerados rumores de peligro también tenían un efecto disuasorio. Una pareja americana que viajaba en el ferry de Algeciras a Tánger en 1896 escuchó varias historias con final sangriento de robos y muertes que presuntamente tuvieron lugar en el interior de Marruecos. ${ }^{30}$ La Cámara de Comercio española en Tánger citaba a un malagueño vendedor ambulante de objetos de latón que atravesaba una región "que no era frecuentada por cristianos" acompañado por su hijo y un sirviente marroquí, añadiendo

25 HARRIS, Walter B.: The Land of the African Sultan. Travels in Morocco, Nueva York, Bromfield \& Co., 1889 , p. 10 .

26 TROTTER, P. D.: Our Mission to the Court of Morocco, Edimburgo, D. Douglas, 1881, p. 287.

27 CÁMARA DE COMERCIO ESPAÑOLA EN TÁNGER, Revista ..., no 92, vol. 11 (1897), p. 10; MARTÍNEZ GARCÍA, Ramón: Una excursion ..., pp. 7-8.

28 LOTI, Pierre: Au Maroc, pp. 25-26.

29 SALMON, Georges: "Essai sur 1'histoire politique du Nord-Marocain", Archives Marocaines, n 2 (1905), pp. 117-120.

30 WORKMAN, Fanny Bullock, y WORKMAN, William Hunter: Sketches Awheel in Modern Iberia, Nueva York, G. P. Putnam and Sons, 1897, pp. 105-106. 
que "por fortuna, siempre lo hemos visto volver a Tánger sano y salvo". ${ }^{31}$ Aunque los peligros eran exagerados, la necesidad de un séquito de empleados y provisiones hacían el viaje por Marruecos, caro y complicado. En la opinión de Walter B. Harris, un personaje muy conocido en la zona y corresponsal en Tánger durante muchos años del Times de Londres, la comparación de viajar por Marruecos con otros destinos como Persia, China o Siria era muy desfavorable. ${ }^{32}$ Para entrar en Marruecos no se necesitaba pasaporte pero este documento garantizaba a los viajeros una ayuda consular en caso de problemas físicos o financieros. ${ }^{33}$ Los viajeros europeos antes de 1900 normalmente no tenían apenas razones para temer por su seguridad siempre y cuando permanecieran en Tánger y en otras comarcas leales al Sultán. Algunos incluso respetaban la exigencia de alquilar los servicios de una escolta armada salida de las milicias del Sultán cuando viajaban fuera de Tánger, lo que era una molestia bastante costosa. ${ }^{34}$ El problema del alojamiento añadía más dificultades cuando se viajaba lejos de los enclaves costeros o insulares. Los albergues de carretera en Marruecos eran rudimentarios y tan fuera de cualquier estándar que la mayor parte de los viajeros europeos aconsejaban montar una tienda de campaña aunque hubiera una posada disponible. Por ejemplo, Richard Ford advertía sobre el funduq de la carretera TángerTetuán era como "un enjambre de parásitos, con patio lleno de animales". Según la colonia militar española, esta posada, que disponía de diez habitaciones, "carece de utensilios y provisiones" y "sirve sólo para alojar a los propios moros" que duermen habitualmente de ocho a diez por habitación. ${ }^{35}$

Casi todos los viajeros europeos que llegaban de tierras lejanas alcanzaban el Estrecho de Gibraltar por barco. Los cuatro días de viaje en tren desde Londres eran considerablemente más rápidos que los nueve días del pasaje en barco de vapor pero la mayor parte de los viajeros venían disuadidos por las largas esperas entre las conexiones y el ruido y traqueteos de los vagones de los trenes españoles. Las dificultades del viaje por tierra hacia el Sur están ilustrados por el destino del Sud-Express, una ruta ferroviaria desde París hasta Casablanca pasando por Madrid, Algeciras, Gibraltar y Tánger. La idea subyacente al Sud-Express era la de coordinar horarios y billetes entre las pequeñas líneas ferroviarias preexistentes a lo largo de la ruta. La línea empezó con su servicio regular semanal en septiembre de 1897 pero sólo circuló durante 43 semanas, transportando el decepcionante total de 580 pasajeros en ambas direcciones desde Algeciras a Madrid antes de ser cancelada. ${ }^{36}$ Por el contrario, cientos de miles de marineros, personal naval, inmigrantes y otros viajeros pasaban a tra-

31 CÁMARA DE COMERCIO ESPAÑLA EN TÁNGER: Revista ..., nº 76, vol. 8 (1894), p. 3.

32 HARRIS, Walter B.: Morocco That Was, Boston, Small, Maynard, \& Co., 1921, p. 232.

33 BAEDEKER, Karl: Spain and Portugal ..., pp. xii-xiii.

34 HARRIS, Walter B.: African Sultan ..., p. 10; POISSON DE LA MARTINIÈRE, Maximilien Antoine Cyprien Henri: Morocco, journeys in the Kingdom of Fez and to the court of Mulai Hassan, Londres, Whittaker \& Co., 1889, pp. 40-41.

35 FORD, Richard: Handbook ..., p. 426; "Itinerario Ceuta-Tetuán,” Centro Geográfico del Ejército, C/5/I, no. 2 .

36 Director General de la Compañía de Ferrocarriles Bobadilla-Algeciras a la Dirección de la Compañía MZA, 24 enero 1906, AHF D/652/1. 
vés del Estrecho cada año, con el añadido de otros miles de pasajeros transatlánticos en ruta hacia Italia y otros puertos del Mediterráneo. ${ }^{37}$

Aun así, la creencia de que la mejora del servicio ferroviario desde Europa estimularía el turismo, movilizó una inversión considerable. En 1888, una compañía londinense consiguió la concesión para construir un enlace desde el centro de comunicaciones de Bobadilla hasta el puerto de Algeciras, donde los viajeros podrían enlazar con la línea regular de ferrys de Gibraltar y Tánger. ${ }^{38}$ En efecto, hacia 1893 la nueva Algeciras Railway Company uniría el Estrecho con la línea férrea principal de Madrid-Málaga. El eje central de esta empresa ferroviaria turística eran dos hoteles: el Reina Victoria de Ronda y el Reina Cristina de Algeciras, dos excelentes muestras de la arquitectura colonial victoriana, situados en el corazón de los pueblos blancos típicos de Andalucía. La integración con la red de ferrocarriles europeos era fundamental para la estrategia de la compañía y, cuando el Sud-Express quebró en 1897, la Algeciras Railway Company lanzó inmediatamente una campaña para reflotarla. Sus directivos escribieron a colegas de otras compañías involucradas en la red del Sud-Express urgiéndoles a reconsiderar su postura, de manera que la firma alargó la línea hasta el muelle de Algeciras, desde donde se embarcaba a los transbordadores hacia África. El ferrocarril también invirtió 25.000 libras para mejorar la principal dársena del puerto de Tánger, un desembolso que alcanzó el $6 \%$ de su capital total. ${ }^{39}$ La Conferencia de Algeciras de 1906 provocó un nuevo interés en la revitalización del Sud-Express pero, bajo un nuevo nombre: Maroc Express. La iniciativa se había archivado en 1898, según un administrador ferroviario español, debido a las "perturbaciones en la vida nacional" de aquella época; ahora, en 1906, "las cosas han cambiado notablemente... como el incremento constante de circulación de viajeros combina con el interés acerca de Algeciras, que aumenta por esta conferencia diplomática... cuya influencia en los asuntos locales de la ciudad no será efímera." 40 Aunque el momento de gloria de Algeciras sería breve, el Maroc Express consiguió mejores resultados en esta ocasión, particularmente durante el pico turístico que se producía entre los meses de octubre y abril. ${ }^{41}$ España -no sólo a nivel territorial sino también económico- era clave, por fin, como enlace de transporte desde Europa occidental y el Magreb.

El mero hecho de cruzar el Estrecho podía generar mucha ansiedad para los no iniciados. A pesar de la gran cantidad de publicidad dirigida a los turistas, la mayor parte de los pasajeros de la Bland Line era gente de la zona. Según el relato del geógrafo y diplomático francés Maximilien de la Martinière, "las cubiertas de los vapores pequeños... están atestadas por una variopinta multitud que sólo encontrarías en barrios

37 BETEGÓN, Javier: La Conferencia de Algeciras: Diario de un testigo, con notas de viajes á Gibraltar, Ceuta y Tánger y el Protocolo oficial, Madrid: Hijos de J. A. García, 1906, p. 47.

38 Dirección General de Obras Públicas al Ingeniero Jefe de la División de Ferrocarriles de Sevilla, 6 octubre 1888, AHF A/131/16.

39 AFFCC D/652/1, Exp. 6, y A/131/16; VAIDON, Lawton: Tangier ..., p. 147. El capital inicial de la Algeciras Railway Company alcanzó a unos 10.900.000 de pesetas, aproximadamente unas 415.000 libras.

40 Director General de la Compañía de Ferrocarriles Bobadilla-Algeciras a la Dirección de la Compañía MZA, 24 enero 1906, AHF D/652/1.

41 Dirección de la Compañía MZA al Director General de la Compañía de Ferrocarriles BobadillaAlgeciras, 25 marzo 1907, AHF D/652/1. 
de los países orientales. Judíos grasientos con ropas repugnantes, árabes renegados... eso en un primer golpe de vista, lo que no nos deja una buena impresión." También había a bordo bastantes españoles. Como muchos recién llegados, Martinière debió ser incapaz de distinguir ese arquetipo judío y moro de los andaluces que hacían la travesía por motivos de trabajo o comercio. Tendrían una ligera diferencia en cuanto a apariencia -incluso vestimenta- y tenderían a comunicarse en la lingua franca, mezcla del español, árabe y rifeño que hablaban sin esfuerzo. En todo caso, el caos de su llegada trastocaría rápidamente la mirada arrogante del francés. El ferry echó anclas muy cerca del muelle principal, desde donde se aproximó una flotilla de barcas llenas de marroquíes "descendientes de antiguos piratas" que agarraban las escalas para "trepar, ágiles como monos, e invadir la cubierta." ${ }^{42}$ Otros viajeros también evocaron esa sensación de asalto de los bárbaros. El barón y escritor de viajes austríaco Ernst von Hesse-Wartegg se quedó perplejo durante la consiguiente batalla campal de veinte o treinta de esos "bandidos del color del café" para meter a los viajeros y sus equipajes en sus barcas, obligando a las histéricas pasajeras a esconderse. ${ }^{43}$ Resultó que esos supuestos piratas no eran tal amenaza sino simples porteadores y guías en busca de clientela. A diferencia de Martinière y Hesse-Wartegg, el puertorriqueño Ramón Martínez García no se quedó tan desconcertado por "el espectáculo de una multitud de lanchas y botes, tripulados por moros, bogando y gritando en su extraño idioma". Reconoció que un cierto grupo de esos hombres eran también de origen español y pudo realizar su desembarco "libre(s) de toda molestia." ${ }^{44}$ De igual forma, lady Howard-Vyse, una turista inglesa, encontró que "la masa de chillones, gritones y gesticulantes árabes" era más una "escena maravillosa" que confirmaba su llegada a un mundo diferente, que una amenaza. ${ }^{45}$

El refuerzo del eje Gibraltar-Tánger abrió un enorme abanico de posibilidades para viajar. En 1900, en menos de tres horas, uno podía pasar por los dos puertos en cualquiera de los tres vapores ingleses por el módico precio de dos pesetas en primera. El control anglo-gibraltareño de esta ruta frustró a los emprendedores del comercio español en Tánger, que se quejaban del planteamiento poco sistemático de su gobierno para fomentar su influencia en la cada vez más europea ciudad marroquí. La Compañía Transatlántica hacía el servicio de Algeciras a Tánger, pero su arancel portuario de 11 pesetas por pasajero lo hacía insostenible, sobre todo cuando el pasaje a través de la bahía de Gibraltar para enlazar con la línea inglesa era barato y cómodo. El propósito de este arancel era fundar una compañía subsidiaria para la línea Cádiz-Tánger, un servicio deficitario de carga y correo que no podría prosperar de otra manera bajo el ambiente imperante de proteccionismo en España y el puerto libre de Gibraltar tan cerca. Como resultado de estas malas políticas, Algeciras era poco competitiva con respecto a Gibraltar a pesar de que la mayor parte de la clientela era española y a pesar del estímulo ferroviario, que llegaba hasta el mismo puerto de Algeciras después de 1893, mientras que Gibraltar permanecía incomunicada por tren. El puerto de Gibraltar despachaba unas tres veces el número de pasajeros de

\footnotetext{
42 POISSON DE LA MARTINIÈRE, Maximilien Antoine Cyprien Henri: Morocco., pp. 3, 6-7.

43 HESSE-WARTEGG, Ernst: Andalusien ..., pp. 378-379.

44 MARTÍNEZ GARCÍA, Ramón: Una excursión ..., pp. 43-44.

45 HOWARD-VYSE, Lady: Winter in Tangier ..., pp. 2-3.
} 
Algeciras, y la mitad del total del número de europeos que llegaban a las costas de Tánger - cifra que subiría desde los 6.901 en 1887 hasta el pico máximo de 17.403 en 1891 (disminuyendo hasta los 14.873 en 1894 como resultado del aumento del servicio directo de vapores a otros puertos marroquíes). ${ }^{46}$

Aunque los datos precisos no están disponibles, la Cámara de Comercio española informó de que los pasajeros que llegaban en un típico barco de vapor desde Gibraltar o Algeciras eran "casi por completo" españoles, "procedentes de pueblos del Campo de Gibraltar." ${ }^{47}$ En comparación con la inmigración española hacia Argelia, más de familias dedicadas a la agricultura, los españoles eran trabajadores del comercio y del transporte que se movían de acá para allá entre Tánger y el Campo de Gibraltar como precaria mano de obra urbana. Una nueva oleada de construcciones en Tánger creó una buena oportunidad de trabajo para los albañiles españoles, especialmente desde que el pachá local prohibió a los obreros marroquíes trabajar en proyectos de construcción extranjera. ${ }^{48}$ Casi todos los años, el balance de las salidas de españoles de la ciudad era casi idéntico al número de llegadas, sugiriendo que el constante crecimiento neto de la población española enmascaraba la naturaleza inestable y transitoria de muchas estancias en la ciudad. ${ }^{49} \mathrm{Su}$ reputación entre la clase media de la comunidad europea de Tánger como "escoria de la población criminal... muchos de ellos medio borrachos, todos ellos más que censurables" ${ }^{50}$ no era del todo inmerecida. Desde la Revolución de 1868 en España, Tánger se había convertido en un nido de anarquistas y otros radicalismos clandestinos cuyos adeptos no estaban bien vistos por la burguesía respetable. Algunos alcanzaron la ciudad después de escapar de la prisión de Ceuta. Muchos otros entraban y salían de la delincuencia común y de casas de beneficencia como la misión franciscana establecida por el padre Lerchundi en 1888 con el apoyo del magnate naviero Claudio López Bru, cuya Compañía Transatlántica fue uno de los pilares del éxito español en Tánger. ${ }^{51}$ Los españoles eran los menos representativos en la categoría de comerciantes. El cónsul español en Tetuán se lamentaba en 1889 de que "por cada cien viajeros ingleses, alemanes, norteamericanos y franceses, quizá un español pone el pie en estas tierras, si llega." ${ }^{52}$

Pero esta visión sesgada pasa por alto la contribución de los españoles al floreciente sector servicios de la ciudad, íntimamente vinculado a su identidad como punto neurálgico de rutas de viaje. El modesto emprendimiento de los españoles se concretó en forma de cafés y cabarets. Estos negocios, que en muchas ocasiones servían de tapadera a negocios de apuestas clandestinas y burdeles, formarían parte de las atracciones para viajeros de todas las nacionalidades. Según la Cámara de Comercio Española en Tánger, unos 100 comerciantes e industriales y 50 propietarios de inmue-

46 CÁMARA DE COMERCIO ESPAÑOLA EN TÁNGER: Revista ..., no 43, vol. 5 (1891), Idem., p. 4; Idem., no 92, vol. 9 (1897), p. 10; MIÈGE, Jean-Louis: L'Europe au Maroc, t. IV, p. 295.

47 CÁMARA DE COMERCIO ESPAÑOLA EN TÁNGER: Revista ..., no 76, vol. 8 (1894), p. 5.

48 MIÈGE, Jean-Louis: L'Europe au Maroc, t. IV, p. 287.

49 BONMATÍ, José Fermín Bonmatí: Españoles en el Magreb, siglos XIX y XX, Madrid, MAPFRE, 1992 , p. 223.

50 HARRIS, Walter B.: African Sultan ..., p. 14.

51 RODRIGO Y AMARILLA, Martín: "Una avanzadilla española en África: el grupo empresarial de Comillas”, en Eloy MARTÍN CORRALES (ed.), Marruecos ..., p. 138.

52 CÁMARA DE COMERCIO ESPAÑOLA EN TÁNGER: Revista ..., no 77, vol. 8 (1894), p. 5. 
bles poseían la considerable suma de 3 millones de pesetas invertidas en la ciudad. ${ }^{53}$ Otros trabajaban como pequeños artesanos, albañiles, jardineros, cocineros y servicio doméstico, siendo todos ellos, el soporte de la expansión del turismo residencial. ${ }^{54}$ Viajar hacia el Este desde Tánger rumbo a Ceuta y Tetuán estaba muy restringido por culpa del traicionero delta del río Oued Suani hasta que los españoles establecieron un servicio de transbordadores para los viajeros y sus animales. Como eran los principales pescadores y cazadores de jabalí y perdiz, los españoles suministraban a los hoteles carne fresca. Su costumbre de criar cerdos, considerados inmundos por sus vecinos judíos y musulmanes, proporcionaba otras comodidades a los colonos europeos.

El papel de los españoles como proveedores de cerdo y otras carnes fue fundamental en el crecimiento del sector turístico pero también generó resentimiento en los sectores más tradicionales. Aquellos que se ganaban la vida suministrando carne fresca a la creciente industria hotelera fueron culpados de esquilmar las reservas de caza. La caza fue crucial para mantener la cohesión de la enorme y cambiante élite social de diplomáticos, comerciantes e invernants de clase alta que había en Tánger. Su actividad favorita era la caza del jabalí con lanzas, una peculiar montería que se llevaba a cabo en las colinas arenosas salpicadas de bosques de pinos al sur del corazón de la ciudad. En esta actividad, practicada por cristianos pero también por musulmanes y judíos, los cazadores a caballo necesitaban la ayuda de los sirvientes locales, agazapados cerca, para obligar a los jabalíes a salir de las retamas hacia campo abierto. Cuando eso ocurría, los cazadores galopaban a través de barrancos y zanjas, por encima de vallas y árboles caídos, intentando atravesar a la bestia con su lanza. ${ }^{55} \mathrm{El}$ nuevo ciclo de expansión turística y urbana amenazó esta emocionante persecución. La disminución de la población de jabalíes impulsó a John Drummond-Hay a actuar en representación de su clase: el ministro británico obligó al Sultán Muley Hassan a conceder un coto de caza especial, prohibido a todos excepto a los miembros de las delegaciones diplomáticas y sus huéspedes y, además, repobló el coto con jabalíes traídos de los bosques andaluces adyacentes a Gibraltar. ${ }^{56}$

\section{El Turismo y el nuevo paradigma urbano}

El predominio del turismo, los viajes y el ocio le confirió a Tánger un aire cosmopolita, pero de una manera bastante diferente a la de otros enclaves turísticos del Mediterráneo como Túnez o Hyères. En comparación con estas dos ciudades coloniales, Tánger carecía de una tradicion previa de ambiente costero y de una clientela aristocrática que le diera prestigio. Aun cuando el asentamiento era antiguo, como ciudad se hizo tabula rasa, imponiéndose las modernas e imperialistas formas de sociabilidad a su caleidoscopio étnico-religioso previo. Aunque el Sultán marroquí continuaba siendo formalmente el soberano, eran los cánones anglo-franceses los

\footnotetext{
53 MIÈGE, Jean-Louis: L'Europe au Maroc, t. IV, p. 288.

54 HARRIS, Walter B.: African Sultan ..., p. 21; BETEGÓN, Javier: La Conferencia ..., pp. $272-296$.

55 POISSON DE LA MARTINIÈRE, Maximilien Antoine Cyprien Henri: Morocco ..., pp. 42-43.

56 FORD, Richard: Handbook ..., p. 425; HARRIS, Walter B.: African Sultan ..., p. 26.
} 
que definían a la alta sociedad local. Resulta bastante paradójico pero el idioma era más una marca de clase social que de identidad étnica. Las élites de todos los grupos étnico-religiosos hablaban en inglés y francés pero la lengua franca de la región era el español, cuyo conocimiento daba a los marroquíes acceso a la sociedad europea de Tánger y conectaba al grueso de la población de Gibraltar con sus vecinos y socios.

El pintoresco paisaje urbano de Tánger fue ganando un aspecto europeo, particularmente en ciertos ensanches suburbanos. La Convención de Madrid de 1880, en la cual el Sultán concedió a los forasteros la posibilidad de tener propiedades, abrió la puerta a una considerable inversión europea. Nuevos barrios de clase media multicultural surgieron fuera de las antiguas murallas, dando lugar a calles en una continuidad de estilo Art Nouveau diseñadas y construidas por empresas y arquitectos españoles. Incluso el arquitecto catalán Antonio Gaudí fue reclutado por sus jefes de la Compañia Transatlántica para diseñar una grandiosa misión franciscana aunque, al final, la obra nunca se realizó. Un área a destacar es el distrito Marshan, un barrio espacioso con zonas verdes donde los europeos y marroquíes ricos construían sus villas de estilo italiano, lo que nos indica que el concepto de clase había empezado a competir con el de etnia como principio fundamental de organización del espacio urbano. ${ }^{57}$ La modernización a la europea de Tánger provocó una mejora en la ciudad vieja en términos de sanidad y comodidades aunque cualquier viajero la encontraría insuficiente: los interiores se inundaban durante las lluvias torrenciales y en muy pocas partes de la ciudad el pavimento era adecuado para soportar el tráfico rodado.

A pesar de tales contratiempos, el Tánger emergente se transformaba en una ciudad cada vez más hospitalaria con los extranjeros. Hacia 1895 ya contaba con señalización y farolas para ayudar a los visitantes a adentrarse en las laberínticas calles de la ciudad. ${ }^{58}$ A ocho millas al Oeste de Tánger, llegar al faro del cabo Spartel -accesible gracias a una moderna carretera construida por las autoridades marítimas- suponía un agradable día de excursión donde los visitantes podrían ver la supuesta tumba de Hércules y disfrutar de maravillosas vistas, refrescos y cerveza. ${ }^{59}$ Los centros de ocio revelaban una especial capacidad de superar la división étnica y eran cada vez más numerosos. En sus memorias, Emily Keene decía que "no había muchos entretenimientos en Tánger" en los primeros años de la década de 1870, lo que era escasamente creíble hacia $1900 .{ }^{60}$ Los espectáculos de la ciudad eran, al principio, para los europeos pero empezaron a ser atractivos para la mayor parte de los nativos musulmanes y judíos. Los viajeros de un cierto nivel podrían esperar invitaciones a bailes y conciertos organizados por las legaciones europeas. Las mujeres de la alta sociedad de Tánger soportaban con dignidad las penurias de una vida en un lugar remoto, tales como llegar a bailes o recitales montadas a lomos de burro con sus elaborados vestidos y peinados intactos. Las sillas de montar eran todo un lujo en Tánger, por no hablar de un coche de caballos. ${ }^{61}$ Los acontecimientos deportivos proporcionaban una ocasión para unir a las diversas comunidades. El Country Club, fundado en

57 MILLER, Susan Gilson: “Making Tangier Modern ...”, pp. 135-139.

58 DROUET, Francis: Au nord de l'Afrique, Niza: Place Sasserno, 1896, p. 150.

59 FORD, Richard: Handbook ..., p. 424.

60 KEENE, Emily: My Life Story, Londres, E. Arnold, 1911, p. 13

61 HOWARD-VYSE, Lady: Winter in Tangier ..., p. 140. 
1898 y patrocinado por los británicos, trajo el tenis, el golf y el cricket a la sociedad más acaudalada: oficiales de las legaciones, ricos comerciantes, nobles marroquíes y turistas aristocráticos. Marroquíes nativos jugaban en el equipo de fútbol local, que atraía a espectadores de todo tipo. ${ }^{62}$

La personificación de la conciencia cívica era la Comisión de Higiene. Aunque este consejo de oficiales consulares europeos se había establecido por primera vez en 1831, su única función, que era la de poner en cuarentena el puerto, se había quedado obsoleta desde hacía tiempo a medida que las nuevas ideas sobre salud pública apostaban por mejorar la ciudad en vez de establecer lazaretos. Un grupo de residentes europeos intentó reactivar la organización basándose en este nuevo énfasis urbano de 1870 pero la Comisión de Higiene y Limpieza como se llamaba ahora, languideció por falta de ingresos y apoyo oficial. A finales de la década de 1880, la Comisión se refundó sobre cimientos mucho más sólidos, ganándose el reconocimiento de las autoridades locales y adoptando un sistema de financiación a base de suscripciones voluntarias. Además del alumbrado público, ésta trabajó para mejorar el pavimento, el alcantarillado y el establecimiento de normativas de edificación. De una manera similar a la cercana Málaga, la Comisión unificó a residentes locales y extranjeros en un conjunto de suscriptores que hacia 1910 alcanzó los 900, extraídos de todas las clases sociales, etnias y religiones. ${ }^{63}$

La posibilidad de que Tánger se convirtiera en un gran centro de turistas de invierno seguiría sin concretarse más que parcialmente, aunque no supuso el fin del modelo de desarrollo urbano basado en estancias breves e itinerantes. La emergencia de una nueva clase alta entre los diplomáticos y comerciantes europeos no negó la deprimente realidad de una ciudad con calles muy mal pavimentadas. Aparte del hedor insoportable procedente de las curtidurías y del aceite de cocinar usado en el atestado barrio viejo, había olores que flotaban en el ambiente como los que procedían de una nueva fábrica de conservas localizada cerca del puerto. ${ }^{64}$ Aun así, la posición geográfica de la ciudad le auguraba una ventaja competitiva para el creciente sector turístico. Su historia única había conferido a Tánger un carácter claramente cosmopolita en un sentido más estricto que en otros enclaves mediterráneos como la Costa Azul, donde el ambiente internacional era inventado. Una situación geográfica privilegiada, una mano de obra políglota y el encanto moruno moderado por una administración europea, habían sido suficientes para atraer a un constante flujo de curiosos desde las últimas décadas del siglo anterior. La posibilidad de vender productos artesanales a los turistas había atraído a miles de marroquíes a la ciudad contribuyendo significativamente a su vida social y económica.

Los cafés, music halls y casinos de estilo europeo que se abrieron atendían a la alta sociedad, turistas y clases populares de forma conjunta. ${ }^{65}$ Algunos europeos estaban

62 BETEGÓN, Javier: La Conferencia ..., p. 296; VAIDON, Lawton: Tangier ..., p. 122; CEBALLOS, Leopoldo: Historia de Tánger ..., p. 250.

63 MILLER, Susan Gilson, "Making Tangier Modern ...”, p. 132. Sobre Málaga, ver PELLEJERO MARTÍNEZ, Carmelo: "El turismo como alternativa económica en la Málaga de principios de siglo. Informe del Cónsul de Francia”, Revista de Estudios Regionales (Málaga) no 42 (1995), pp. 306-311.

64 VAIDON, Lawton: Tangier ..., p. 122.

65 MILLER, Susan Gilson, "Making Tangier Modern ...”, p. 139. 
encantados con los bazares bereberes de la Medina donde podían acumular souvenirs, y que, al ser un negocio cada vez más floreciente, estimulaba la complicidad popular en la europeización de la ciudad. El elegante Kursaal francés abrió en 1912, una casa de apuestas que rápidamente llegó a ser toda una institución en la vida social, alojando eventos como el baile sionista o la Orquesta Castillo. ${ }^{66}$ Entretenimientos tan españoles como la zarzuela o el flamenco se encontraban en los barrios populares, así como espectáculos de dudosa danza "oriental" representados por bailarinas judías y españolas en sótanos para ingenuos turistas. ${ }^{67}$ Los españoles estaban muy ligados a las apuestas clandestinas y los negocios de prostitución, una asociación que dañaría su reputación entre la comunidad internacional en las momentos más decisivos del nuevo siglo. La playa -espacio cosmopolita por excelencia del siglo XX- era un sitio de moda para que los europeos se dejaran ver, no dándose un baño pero sí montando a caballo y socializando. Los días soleados y agradables, la playa estaba llena de multitudes bien vestidas, hombres y mujeres representantes de todas las comunidades étnicas de la ciudad. Algunos sentados en las características sillas con respaldo de lona, atendidos por camareros en smoking, mientras que otros se instalaban directamente sobre la arena. Espontáneos desfiles ecuestres hacían las delicias de los visitantes y, hacia 1889 , una sección de la playa fue provista de casetas para los bañistas y dos cafés al aire libre, mientras que las playas más alejadas sirvieron como vertederos hasta $1936 .{ }^{68}$

Los hoteles de la ciudad apenas parecían estar en un país musulmán. Al llegar al Hotel de France en 1894, Hesse-Wartegg "se quedó profundamente decepcionado" por las camas parisinas y un vestíbulo equipado con periódicos europeos y un piano: "No puedes escapar de Europa" ${ }^{69} \mathrm{Al}$ mismo tiempo, el casco antiguo de la ciudad, que incluía los cementerios musulmán y judío, continuaba presentándose a los viajeros como un espectáculo novedoso. Los rifeños solían ser tenderos y artesanos en el barrio comercial, aunque los puestos españoles de licor y tabaco fueron cada vez más frecuentes en los zocos o mercadillos al aire libre. ${ }^{70}$ La ciudad contaba con 22 sinagogas junto con cinco mezquitas y varias capillas de morabitos, una especie de ermitaños musulmanes. Éstas atraían un flujo constante de peregrinos musulmanes cuyas ofrendas generaban un considerable ingreso para las hermandades residentes en Tánger que las mantenían. Los comerciantes ambulantes musulmanes que venían a Tánger para trabajar en el zoco también visitaban las capillas de morabitos, lo que ilustra que para los marroquíes los motivos de comercio y turismo también se entremezclaban con frecuencia. ${ }^{71}$ El creciente número de europeos en Tánger puso a

66 Le Petit Marocain, 19 June 1925.

67 POISSON DE LA MARTINIÈRE, Maximilien Antoine Cyprien Henri: Morocco ..., pp. 15-16.

68 BUDGETT-MEAKIN, James Edward: The Land of the Moors: A Comprehensive Description, Londres, Swan Sonnenschein \& Co., 1901, p. 103; HARRIS, Walter B.: African Sultan ..., p. 21. Una foto ilustrando la sociabilidad en la playa de Tánger aparece en LAREDO, Isaac: Memorias de un viejo tangerine. Madrid: C. Bermejo, 1935, p. 28.

69 HESSE-WARTEGG, Ernst: Andalusien ..., p. 383.

70 LOTI, Pierre: Au Maroc, p. 3; DROUET, Francis: Au nord..., p. 142; BUDGETT-MEAKIN: Land of the Moors ..., pp. 98, 101.

71 MICHAUX BELLAIRE, Édouard: "Quelques tribus de montagnes de la region de Habt", Archives Marocaines, n 17 (1911), p. 71; SALMON, Georges: "Essai ...” pp. 117-120. Una foto del santuario se repro- 
prueba la santidad de las capillas, cuya entrada estaba prohibida a los no creyentes, y finalmente algunas hermandades musulmanas levantaron muros para mantener lejos a los espectadores europeos. ${ }^{72}$ "Ver un poco de África" el día antes de "volver a Europa por la tarde" era posible sin dejar Tánger, observó Hesse-Wartegg: "a los típicos turistas afeminados les gusta esto". ${ }^{73}$

Esta invocación al afeminamiento era una señal de distinción entre viajero y turista, habitual en la cultura victoriana, aunque cada vez más pasada de moda. Hacia finales del siglo XIX los europeos en el Mediterráneo tendían a usar los términos indistintamente, sin una diferencia aparente en su connotación. La asignación de uno de los dos términos no seguía criterios de género ni denotaba un cierto nivel de aventura. El viaje a la región continuaba ofreciendo una buena dosis de emoción, pero cada vez era una experiencia menos arriesgada. Mujeres procedentes de metrópolis muy distantes ocupaban espacios públicos impensables para las familias autóctonas de antiguo linaje. Al igual que para las principales guías de viaje, el paso a Tánger era obligado para la proliferación de libros que contaban las peripecias de mujeres viajeras a través del Sur de España. Blasco Ibáñez, que llevaba una pistola para protegerse, se sorprendió al observar a un par de señoritas sin compañía en el ferry de la Bland Line desde Gibraltar, atribuyéndolo a la "libertad inglesa". ${ }^{74}$ Más descarada todavía fue una chica americana, a la que Walter Harris oyó por casualidad en el ferry mientras le anunciaba a su madre que se casaría con un moro. ${ }^{75}$

La habilidad de las británicas para circular libremente era un motivo de orgullo, al menos para Harris, un signo de la beneficiosa influencia británica. En sus nostálgicas memorias de 1921, Morocco That Was, Harris recuerda la seguridad que había en la carretera a lo largo de los 60 kilómetros que separaban Tánger de Tetuán, por donde las señoras británicas conducían solas, y "una turista a menudo circulaba... acompañada sólo por un guía nativo." 76 Esta etapa, recordada con melancolía por Walter Harris, cuando las damas inglesas podían recorrer tranquilamente los caminos a las afueras de Tánger, llegó a su fin con el siglo, ya que el bandolerismo bajó de las montañas y se acercó a las puertas de la ciudad. En 1896, el Sultán informó a los cónsules en Tánger de que ya no había garantía de seguridad para los viajeros que se adentrasen hacia el interior, una medida preventiva ante los rumores de agitación en su reino. ${ }^{77} \mathrm{La}$ inquietud acerca de la excesiva influencia europea dividió profundamente a la sociedad marroquí tanto en Tánger como en muchos otros lugares. El joven sultán Abdel Aziz (r. 1894-1904), fue considerado por muchos como demasiado pro-europeo, entregado a su pasión por las bicicletas, los fuegos artificiales y otros artefactos importados, mientras ignoraba sus responsabilidades hacia su propio pueblo y su fe. ${ }^{78}$ Hacia la primera década del siglo XX, furiosos alzamientos populares en

\footnotetext{
duce en LAREDO, Isaac: Memorias ..., p. 64.

72 SALMON, Georges: "Essai ...", pp. 117-118.

73 HESSE-WARTEGG, Ernst: Andalusien ..., p. 403.

74 BLASCO IBAÑEZ, Vicente: Crónicas de viaje, Valencia, Ediciones Prometeo, 1967, p. 84.

75 HARRIS, Walter B.: African Sultan ..., p. 4.

76 HARRIS, Walter B.: Morocco That Was, pp. 255, 261.

77 WORKMAN, Fanny Bullock, y WORKMAN, William Hunter: Sketches Awheel ..., p. 129.

78 PENNELL, C. R.: Morocco since 1830: A History, Nueva York: New York University Press, 2000, pp. 121-124.
} 
distintos puntos del Imperio hicieron surgir pretendientes que cuestionaban la legitimidad del Sultán. ${ }^{79}$ A juzgar por los criterios de expansionismo urbano e integración social que estaban teniendo lugar en Tánger, Abdel Aziz no estaba complemente solo en su amor por Europa y su cultura. En distritos rurales, incluyendo los que estaban al lado de Tánger, la escala de conflictos violentos coció a fuego lento la enemistad de clanes favorables a la presencia europea y al Sultán contra las milicias nacidas del populismo xenófobo.

El más temido de los rebeldes populistas de Marruecos era Muley Ahmed Ben Muhammed el-Raisuni. Raisuni descubrió pronto que secuestrar turistas proporcionaba mejores rescates -más de 70.000 duros, unas 13.000 libras- que secuestrar marroquíes o trabajadores españoles, poco considerados por sus gobiernos. ${ }^{80}$ Durante su visita a Tánger, Vicente Blasco Ibáñez no quiso aventurarse más allá de las murallas de la ciudad, explicando el peligro con tensa empatía:

Para nosotros es un bandido; para los moritos belicosos y patriotas es un héroe marroquí que no quiere conformarse con la invasión de los europeos; y saca provecho de ellos, poniendo a precio sus cabezas, mientras llega el momento de sublevarse contra un sultán renegado que come con los extranjeros, monta en bicicleta y en automóvil y tiene en las cárceles a los musulmanes puros y fieros que protestan contra la intrusión lenta de los cristianos, en este país de muerte y olvido, último refugio del fatalismo musulmán. ${ }^{81}$

Raisuini reunió una potente milicia gracias al dinero de los rescates de los viajeros europeos. Se ganó el desprecio internacional con la captura de, entre otros, Walter B. Harris, corresponsal del Times de Londres en 1903, y del rico greco-estadounidense Ion Perdicaris al año siguiente. Como parte del rescate de este último, bajo presión estadounidense, Abdel Aziz le garantizó a Raisuni el título de Qaid de Tánger. Durante los dos años siguientes, Tánger vivió bajo un arbitrario reino de terror $y$, aunque muchos habitantes europeos abandonaron la ciudad, unos cuantos sufrieron intimidaciones y robos en sus propiedades. Se elevaron voces a favor de un mayor control europeo sobre la ciudad, y los poderes internacionales presionaron al Sultán para que capturara a Raisuni. En la Conferencia de Algeciras de 1906, el cerco europeo sobre Tánger se estrechó. Los firmantes aprobaron la creación de una fuerza policial municipal supervisada por españoles y franceses y autorizaron a la Comisión de Higiene para recaudar todos los ingresos procedentes de los tributos municipales sobre la propiedad..$^{82}$ La contribución más inmediata de los turistas y colonos europeos al proceso de consolidación colonial fue conseguir más poder para aquellos encargados de protegerlos.

\footnotetext{
79 MILLER, Susan Gilson: A History of Modern Morocco, Nueva York: Cambridge University Press, 2013, pp. 58-69.

80 HARRIS, Walter B.: Morocco That Was, p. 246.

81 BLASCO IBÁÑEZ, Vicente: Crónicas ..., p. 92.

82 STUART, Graham: The International City of Tangier, $2^{\mathrm{a}} \mathrm{ed} .$, Stanford, Stanford University Press, 1955 , p. 58 .
} 


\section{Crisis y frustración}

La reorganización político-administrativa de Tánger como colonia internacional en 1923 supuso un obstáculo para el turismo aunque también hizo más urgente si cabe su desarrollo. Con el resto de la costa marroquí bajo control francés y español, estos gobiernos decretaron una serie de medidas para promover el comercio interior y exterior en sus respectivas zonas, dejando languidecer al puerto comercial de Tánger. En la zona francesa, Casablanca, que había sido un puerto menor en 1900, sobrepasó a Tánger como puerto más importante del país hacia 1930; su volumen de negocio se había multiplicado por 16 en dos décadas mientras que el de Tánger apenas lo había hecho por $3 .^{83}$ Más aún, después de la crisis bursátil de 1929 la construcción, que había sido la principal fuente de empleo para emigrantes españoles y la más importante fuente de ingresos para el municipio, se paralizó.

Al mismo tiempo, la economía turística local sufrió un severo golpe. El Estatuto de 1923 prohibía expresamente los juegos de azar en la Zona Internacional por respeto a las leyes marroquíes y a las leyes de los países firmantes del estatuto. Pero como muchos residentes en Tánger no eran ciudadanos de los países firmantes, continuaron con su actividad con total inmunidad. Enfrentándose a las nuevas condiciones, con la competencia de los establecimientos alemanes y portugueses, el director del Kursaal francés pidió un levantamiento de la prohibición. El Comité de Control, el nuevo consejo ejecutivo de los cónsules europeos, respondió imponiendo una exhaustiva legislación que ilegalizaba cualquier juego en todo su territorio. Los grandes hoteles y los clubes sociales suspendieron todo tipo de juego de azar, pero los vendedores españoles del Gran Zoco continuaron sin dejarse intimidar y sus máquinas tragaperras seguían ahí para quien quisiera buscarlas y encontrarlas. ${ }^{84}$

Pronto quedó claro que legalizar el juego era una condición sine qua non para cualquier plan que ambicionase desarrollar el turismo en Tánger. Los casinos de Tánger databan de los primeros asentamientos europeos en el siglo XIX, constituyendo la gallina de los huevos de oro, la "vache à lait" (vaca lechera) en palabras textuales de una editorial. ${ }^{85} \mathrm{~A}$ pesar de que la ley islámica proscribía el juego, su prevalencia en Tánger era un claro testimonio del carácter europeo de la ciudad. Los ingresos hacían rentables muchos hoteles y suministraban ingresos extra para comerciantes de toda Europa. Es más, éstos mantenían a las filiales española y francesa de la Cruz Roja, la oficina de turismo, el dispensario, iniciativas educativas y otras instituciones de beneficencia. Aunque la población musulmana y judía no apostaban, casinos como el Kursaal les proporcionaba empleo y funcionaba como centro de la vida social de la ciudad. De manera más informal, los españoles organizaban innumerables sorteos de lotería en la trastienda de sus establecimientos. La Asamblea Legislativa de la Zona Internacional de Tánger, que representaba los intereses de los negocios coloniales, defendía vehementemente el fin de la prohibición en todas partes. La idea ganó sim-

\footnotetext{
83 Cámara de Comercio Internacional de Tánger, documento sin fecha (1933), AGA (Archivo General de la Administración) 10: 54/16134.

84 Onofre Zapata, Presidente del Kursaal Français, al Presidente del Comité de Control, 10 junio 1925 , AGA 10: 54/16116.

85 Le Petit Marocain, 19 junio 1925.
} 
patías entre varios cónsules extranjeros del Comité de Control, el delegado británico abogó por "mirar para otro lado" ante cualquier infracción de la ley. ${ }^{86}$ En 1929, el Comité de Control recibió dos peticiones solicitando la restauración de las apuestas. Una estaba firmada por 253 líderes del comercio local, mientras que la otra mostraba las firmas, muchas de analfabetos, de 138 musulmanes locales, entre ellos botones, guías turísticos, comerciantes del bazar y propietarios de carretas de burros. ${ }^{87}$

Sólo a partir de la década de 1930, los líderes de Tánger empezaron a concebir el turismo como un sector económico al que aplicar principios de dirección y administración. En 1929, el alcance de la acción del Comité de Control en este sentido se limitaba a aprobar fondos para construir casetas de playa para el creciente número de bañistas, muchos de los cuales eran probablemente lugareños. ${ }^{88}$ Cuando la Cámara de Comercio buscaba salidas para superar los obstáculos de este gobierno colectivo, el turismo y el juego empezaron a parecer el remedio mágico. En mayo de 1930, un hombre, del que desconocemos su nombre, que asistía al encuentro de la Cámara de Comercio Internacional cogió el micrófono para urgir a los intereses comerciales de Tánger a considerar las posibilidades del turismo. En su informe para el Comité de Control, la Cámara consideró que merecía la pena dedicarle una página entera a los comentarios de este hombre quien,

...desde un brillante cuadro nos ha paseado a través de Europa, de la Costa de Plata a la Costa Azul francesa e italiana. Nos ha hecho visitar las costas tan ricas del Atlántico español, las grandes playas de Bélgica, las ricas ciudades como Spa, como Baden... El orador nos ha demostrado que Tánger gracias a su situación geográfica podía canalizar fácilmente hacia ella una corriente turística y de veraneo de las más importantes. Nuestro clima suave y atemperado permite tanto en invierno como en verano una oleada de viajeros, invernantes y veraneantes. Nuestra playa única es una atracción que envidian mucho los balnearios de moda. ${ }^{89}$

El informe de la Cámara continuaba diciendo que "por lo tanto hay que industrializar nuestra Zona en este sentido." Tal y como estaba, Tánger recibía un relativo gran número de turistas si lo comparamos con lugares como Ceuta y Casablanca (unos 43.000 en 1934) pero eran básicamente británicos y españoles que venían de Gibraltar y otras zonas cercanas, poco dados a permanecer mucho tiempo. ${ }^{90} \mathrm{La}$ Cámara propuso un plan de urbanización de los barrios situados al Este (cerca de la playa), la construcción de un casino (posiblemente también un campo de golf, una plaza de toros o un spa) y formas de financiación municipal para estos proyectos. Este último reto, continuaba el informe, requería para tan ambicioso proyecto "abrir en los hoteles salas de juego, el único modo de subsistir, y llegar a encontrar los medios necesarios para dar vitalidad a un organismo tan potente". ${ }^{91}$

\footnotetext{
86 Cónsul de Gran Bretaña en Tánger al Presidente del Comité de Control, 20 julio 1925, AGA 10: $54 / 16116$.

87 Comité de Control, reunión de 26 julio 1929, AGA 10: 54/16116.

88 AGA 10: 54/16070.

89 “Assemblée Générale du 15 juin 1930, Rapport du Comité,” AGA 10: 54/16128.

90 CEBALLOS, Leopoldo, Historia de Tánger ..., p. 178.

91 “Assemblée Générale du 15 juin 1930, Rapport du Comité,” AGA 10: 54/16128.
} 
Para responder a la creciente frustración a cerca de las desventajas competitivas que la prohibición impuso a Tánger, el administrador de la zona francesa propuso la cuestión de legalizar el juego en varias ocasiones a lo largo de la década de los treinta. Aunque la mayoría del Comité de Control veía las ventajas de esta propuesta, el delegado español ejerció continuamente su veto. El argumento español se basaba insistentemente en el efecto adverso del juego en la sociedad. Cuando les aseguraron que los nativos tendrían prohibido el acceso a las salas de juego, los españoles replicaron que Tánger estaba demasiado cerca del territorio español y sus colonias para transigir con el juego.

Como alternativa, el delegado español sugirió construir una plaza de toros, un remedio que había aportado considerables ingresos a Ceuta. La alternativa española se consideró, como cabía esperar, un fracaso por los otros miembros del Comité, quienes prosiguieron con eternas discusiones sobre la dudosa moralidad de los juegos de azar, el toreo y la caza. Una plaza de toros no sólo requería modificar el Estatuto Internacional sobre la crueldad animal sino que, en palabras del delegado francés, el espectáculo español por antonomasia estaría "fuera de lugar en un centro internacional como Tánger”. A pesar de que la española era la comunidad extranjera más numerosa de la ciudad, no había ninguna posibilidad de hispanizar su vida social ${ }^{92}$.

La actitud desafiante a la que los tres cónsules españoles consecutivos se aferraron en su postura anti-juego estaba basada, al fin y al cabo, en intereses nacionales. Por un lado, los españoles tenían todos los motivos para bloquear una iniciativa que competiría con los esfuerzos turísticos de Ceuta y los enclaves turísticos emergentes alrededor de Málaga. Además era improbable que la República hubiera permitido a los intereses de una incipiente industria turística influir en su diplomacia internacional (esto no ocurriría antes de los años cincuenta). Viendo cómo tantos grupos de presión habían favorecido el juego y la promoción turística en general, y el entusiasmo entre el resto de los delegados del Comité de Control por adoptar esta solución a los problemas económicos de Tánger, es muy sorprendente que no se pudiera, aparentemente, hacer nada por persuadir a los españoles a retirar su veto. Tras el inicio de la Guerra Civil española, que diezmó la economía de Tánger, los líderes municipales continuaron centrados en la cuestión del juego. Los líderes de la ciudad soñaban con emplear los ingresos procedentes del juego para construir un hipódromo (que competiría con el de Gibraltar) y, "para las clases medias y bajas", un estadio municipal. ${ }^{93}$ Incluso en 1938 con el gobierno republicano sitiado, perdiendo rápidamente credibilidad en Tánger y con muchos atrasos en sus pagos a las arcas municipales, los españoles seguirían sin considerar un quid pro quo.

La mejor explicación para la intransigencia española en la cuestión del juego pasaría totalmente desapercibida en la memoria de la ciudad pero es muy significativa para entender su destino y el de su región. El cónsul español Prieto del Río mantuvo su postura habitual cuando otros delegados le presionaron en una audiencia en 1938, pero enigmáticamente añadió: "Tengo intereses que proteger y no confío en ciertos

92 Comité de Control, reunión de 24 junio 1931, AGA 10: 54/16116.

93 Comité de Control, reuniones de 8 agosto 1938 y 20 agosto 1938. AGA 10: 54/16132. 
empleados de la policía ni en los tribunales de Tánger". ${ }^{94}$ Prieto no detalló a qué se refería exactamente con este comentario pero la insinuación al crimen organizado era evidente. Los españoles dominaban el fraude organizado en Tánger y, tanto si Prieto estaba personalmente conectado, como si simplemente temía represalias, su comentario sugiere que se enfrentaba a presiones para evitar el menoscabo del monopolio extraoficial sobre el juego.

\section{Conclusiones}

Tanto si los miembros de los sindicatos ejercían tanta influencia sobre el poder ejecutivo, la policía y los jueces, como si no, la incapacidad del Comité de Control para legalizar el juego pasando por encima de una sola objeción, reveló la debilidad del Estatuto Internacional. Considerando que su predecesora, la Comisión de Higiene, había supuesto el gobierno municipal más efectivo de Marruecos, las nuevas exigencias de los cónsules acabaron con las demandas de los políticos locales. Con el Estatuto Internacional de 1923, Tánger se transformó en una especie de huérfano político, una ciudad internacional que disfrutaba de las ventajas de no estar sometida a un imperio, gobernada por un consejo ejecutivo sólo capaz de actuar cuando todos los poderes coloniales representados estaban de acuerdo por unanimidad. El resultado atrofió las perspectivas de Tánger como puerto comercial y como centro turístico. Una mezcla de ventajas geográficas y climáticas, una sociedad aristocrática, una masa laboral española y su encanto oriental habían impulsado el espectacular desarrollo urbano en décadas precedentes. Esos mismos factores conspiraron para impedir que se consolidase como gran enclave turístico del Mediterráneo.

Traducción: Ana MORENo GARRIDO

94 Comité de Control, reunión de 23 julio 1938. AGA 10: 54/16132. 